\title{
Narcedalia Piedrotas: el horror de la seducción visual. Costales de huesos en Colombia y México
}

\author{
Mauricio Duarte*
}

\section{Resumen:}

Este artículo analiza la novela mexicana Narcedalia Piedrotas (1993), escrita por Ricardo Elizondo Elizondo y considera para ello los acontecimientos enunciados como falsos positivos en la Colombia contemporánea. Esta lectura regresa al texto ya canónico del desierto mexicano a partir de los violentos acontecimientos derivados de la implementación de una directiva oficial colombiana con el propósito de entender las violencias que se viven en el pueblo mexicano de Perdomo muy cerca de la frontera. Dicho así, se rastrearán los prejuicios y las conductas sociales que rigen en aquel pueblo demostrando cómo estas se enconan en contra del personaje Juana María en virtud de su apariencia y sus relaciones sentimentales. Al final, se podrá entender el engaño del cual es objeto Juana María y la sustracción de su identidad, cuyo propósito no es otro que presentarla como un costal de huesos sobre el cual imputar crímenes. Este artículo revela una política de ordenamiento social que utiliza a la sociedad y a sus instituciones para garantizar la continuidad de las desigualdades.

\section{Palabras clave:}

Falsos positivos, Colombia, narcotráfico, literatura del norte.

${ }^{*}$ Gulf University for Sciences and Technology. 
A menudo acudimos a la literatura para explicarnos la vida misma pero muy pocas veces nos proponemos hacer lo contrario. A menudo encontramos estrictas maneras de aproximarse a las letras que exigen de estas una abstracción de la vida que permita crear a partir de lo esencial una memoria colectiva. Volviendo a leer después de casi dos décadas de su publicación Narcedalia Piedrotas (1993), novela ya canónica de la literatura del norte de México, escrita por Ricardo Elizondo Elizondo, y de reflexionar sobre ciertos eventos ajenos a la realidad de Perdomo, el pueblo fronterizo en el que se viven los cambios sociales de una economía global dentro de la novela, hemos descubierto concordancias que emergen del acontecer histórico de Colombia. A pesar de lo inusual de esta relación que, como veremos adelante se anuda a la implementación del engaño en contextos de violencia, creemos que en este caso lo que ha ocurrido en Colombia nos permite esclarecer aún más la novela de Elizondo Elizondo y viceversa.

Nos explicamos. Este trabajo es en primera instancia un intento por iluminar la novela de Elizondo Elizondo a partir de una serie de acontecimientos históricos colombianos enunciados como los falsos positivos acaecidos alrededor de 2006. Vale aclarar por ahora que el término falsos positivos indica en aquel contexto una conducta social lucrativa dentro de las políticas de seguridad democrática que estimuló el asesinato extrajudicial de sujetos en Colombia, durante la presidencia de Álvaro Uribe Vélez. Durante los últimos años, las denuncias de las víctimas y las investigaciones judiciales han permitido entender esta práctica y su organización sistemática. Teniendo en cuenta dichas conclusiones intentaremos explicar el desgarrador desenlace de la novela Narcedalia Piedrotas y así examinar hasta qué punto la trama concuerda con la violenta conducta revelada tras los llamados falsos positivos. De este modo, se podrá colegir que el texto de Elizondo Elizondo puede leerse hoy en día como una novela que a la par denuncia otra distante sociedad confabulada alrededor del poder y el lucro. Para cumplir con este propósito, primero vamos a reseñar el contexto de los falsos positivos, formulando un procedimiento que permita ser aplicado a la crítica literaria. A partir de este punto se realizará una lectura comparativa 
entre los falsos positivos y la novela en cuestión. Nos interesa aquí denotar cómo se ejecuta el engaño como tal dentro de la novela, que al incorporar el asesinato de una joven personaje nos pone a las puertas de un momento terrible en el que se sustrae la identidad de la víctima en beneficio de su victimario.

\section{Los falsos positivos: el teatro de la guerra}

De acuerdo con un texto aparecido en el semanario colombiano Semana, el "escándalo" de los falsos positivos salió a la luz pública a mediados de 2007, tras una historia que puede parecer mítica. En ese entonces, según dicta el editorial, un soldado colombiano se reunió con representantes de las Naciones Unidas para denunciar las desapariciones forzadas que estaba ejecutando el ejército. ${ }^{1}$ Según la versión del soldado, el ejército seleccionaba, persuadía y asesinaba civiles para luego hacerlos pasar como miembros de grupos guerrilleros. Esta denuncia a primera vista les pareció inverosímil a muchos funcionarios, pues según el testigo, la brigada a la que este mismo pertenecía había asesinado a su padre mientras el militar estaba de licencia. Por esta razón, el soldado afirmó que tuvo que abandonar las filas y buscar el respaldo de las organizaciones internacionales. A partir de este momento se desencadenaron múltiples investigaciones dentro y fuera de las unidades castrenses. Pesquisas que dieron lugar a la investigación exhaustiva del posterior caso de once jóvenes desaparecidos en la localidad de Soacha, ${ }^{2}$ cerca de

${ }^{1}$ Otras fuentes mediáticas y organizaciones no gubernamentales han afirmado que los falsos positivos salieron a la luz pública el 7 de septiembre de 2006. Este día el comandante del ejército en aquel entonces, Gral. Mario Montoya, rectificó ante la prensa que el carro bomba que había estallado en la escuela militar el 31 de julio de 2006 no había sido plantado por las Farc, sino por "personas inescrupulosas", entre las que se encontraban miembros del ejército. En este atentado resultaron 15 heridos y un habitante de la calle asesinado.

${ }^{2}$ Los cuerpos de los once jóvenes asesinados fueron encontrados el 23 de septiembre de 2008. Los nombres de las víctimas reconocidas son Fair Leonardo Porras Bernal, Julián Oviedo Monroy, Diego Armando Marín Giraldo, Jaime 
Bogotá en 2008 y en el posterior retiro forzoso de 26 oficiales de las fuerzas militares. Desde entonces ha sido tal el interés social por los falsos positivos que, además de facilitar frecuentes titulares de prensa, el otrora burgomaestre de Bogotá, Antanas Mockus, creó una tarjeta navideña virtual para denunciar el rechazo colectivo ante dichos acontecimientos. Así, mientras las investigaciones estaban en curso, los medios de comunicación se ocuparon de difundir las versiones oficiales y las frecuentes rectificaciones de los representantes del gobierno, incluyendo al entonces presidente Álvaro Uribe Vélez.

En el contexto de seguridad democrática ${ }^{3}$ diseñado por Uribe Vélez, la investigación de los falsos positivos ha permitido rastrear las conexiones entre las operaciones militares y el beneficio económico. Uno de los elementos clave para evaluar este vínculo ha sido la directiva ministerial aprobada en 2005, en la cual se estableció una secreta economía entre el resultado de los operativos militares que incluían "la captura y el abatimiento" de delincuentes y una

Steven Valencia Sanabria, Daniel Alexander Martínez, Jhon Nelson Gómez y Víctor Fernando Gómez. Cabe anotar que en este caso el nombre de las víctimas ha sido remplazado discursivamente por una estadística: once. Al contrario, la organización Madres de Soacha, creada a partir de estos hechos, tiene el objetivo de mantener viva la memoria de las víctimas y reclamar al estado la verdad sobre los hechos.

${ }^{3}$ En Politica de Defensa y Seguridad Democrática, un documento publicado en 2003 por la presidencia de la república de Colombia, se incluye una carta firmada el 16 de junio de 2003, en la que Uribe Vélez define lo siguiente acerca de su programa: "La Seguridad Democrática es lo que se requiere para garantizar la protección de los ciudadanos. Que el Estado proteja a todos por igual y sin distinción, para que todos los colombianos puedan disfrutar de sus derechos" (5). Luego agrega: "La lucha es de la soberanía de los Estados y de las naciones democráticas contra la soberanía del terrorismo. La lucha es de todos contra el terrorismo". Así como lo siguiente: "Requerimos eficacia con transparencia. Eficacia, que se mide en resultados, y transparencia, que se mide en la observancia de los derechos humanos" (6). Y finalmente: "El imperio de la ley es también garantía de desarrollo y prosperidad económica" (7).

${ }^{4}$ Directiva ministerial 029 de 2005 del 17 de noviembre. Este documento se dio a conocer por los medios de comunicación revelando los criterios de 
estructura de recompensas. A partir de entonces, el panorama de los derechos humanos en la guerra contra el terrorismo -la guerrilla y el narcotráfico- se agudizó apuntando además a una exigua auditoría y a la falta de transparencia con la que se administró el erario en este caso. Ya en 2009, el comisionado de las Naciones Unidas, Philip Alston, precisó que si bien no existían aún evidencias contundentes para involucrar de plano al gobierno y el ejército colombianos, tampoco existía un acervo que probara lo contrario. El investigador concluyó al final de su breve estancia en Colombia que estos graves hechos podrían ser considerados como asesinatos premeditados, y que el caso de Soacha en ningún momento podría entenderse como un evento inconexo con respecto a otros acaecidos en otras regiones de Colombia. Alston sintetizó los falsos positivos de la siguiente manera:

The phenomenon is well known. The victim is lured under false pretenses by a "recruiter" to a remote location. There, the individual is killed soon after arrival by members of the military. The scene is then manipulated to make it appear as if the individual was legitimately killed in combat. The victim is commonly photographed wearing a guerrilla uniform, and holding a gun or grenade. Victims are often buried anonymously in communal graves, and the killers are rewarded for the results they have achieved in the fight against the guerillas ("False positives"). ${ }^{5}$

valoración que sostenían una economía secreta justificada en las guerras contra la guerrilla y el narcotráfico.

5 "La dinámica se conoce muy bien. La víctima es llevada con un señuelo hacia un lugar apartado por un 'reclutador'. Una vez allí, el individuo es asesinado por miembros de las fuerzas militares. Entonces, la escena es manipulada para hacer parecer que el individuo fue asesinado en un combate legítimo. La víctima es generalmente fotografiada luciendo un uniforme de la guerrilla y en poder de un arma o de una granada. Las víctimas suelen ser enterradas en fosas comunes, mientras que los asesinos son recompensados por los resultados obtenidos en su lucha contra las guerrillas" (mi trad.).

El informe final de Alston fue publicado en 2010 ("Report”). 
De esta manera se internacionalizó un hacer sistemático de las fuerzas militares cuya metodología recreó escenografías del terror localizando civiles inocentes en el conflicto armado, mientras suministraba falsas evidencias que eliminaban la identidad de las víctimas. Así se revelaba la efectividad de la estrategia que justifica la violencia como instrumento para promover el desarrollo económico y la pacificación del país acuñada en las políticas de seguridad democrática.

\section{Narcedalia Piedrotas: "el dólar es el lenguaje”,}

Ricardo Elizondo Elizondo (1950-2013) es con frecuencia acuñado entre los narradores del desierto del norte de México, que junto con Gerardo Cornejo, Jesús Gardea, Daniel Sada y Severino Salazar surgieron en la década del setenta. Su escritura ha estado impregnada por las búsquedas históricas y lingüísticas en un contexto cuya lejanía con la capital mexicana y su cercanía con los Estados Unidos marcan la clave de una región que con urgencia tuvo que urbanizarse. En la novela Narcedalia Piedrotas explora estas preocupaciones a través de su protagonista Narcedalia Vega y su familia, quienes entre una y otra generación viven entre los años veinte y setenta del siglo XX. Narcedalia, al igual que los Vega, se caracteriza por capitalizar las pocas oportunidades que le brinda esta árida región multiplicando con frecuencia sus propiedades. En la narración tanto el padre como la madre de Narcedalia ocupan un papel casi intrascendente pero no sucede lo mismo con sus tres hermanos. Por ejemplo, su hermana Guadalupe mantiene una presencia narrativa aun cuando a temprana edad decide abandonar la casa familiar e internarse en un convento de clausura. De la misma manera, sus dos hermanos Melchor y Tomás ocupan un lugar preponderante en la vida de Narcedalia pero todavía más importante después de que

${ }^{6}$ Declaración de Ricardo Elizondo Elizondo en entrevista con Juan José Flores Nava. 
estos son asesinados. Este hecho ocurre luego de que "el cabrero", un humilde vecino, advirtiera la irresponsabilidad de Melchor frente al embarazo de su hija Sofía, con quien mantenía una relación. Otros personajes sustanciales para el desarrollo de la historia de Narcedalia Vega son su esposo Valentín y su hijo Víctor. A través de ellos se conectan las tensiones de la novela en tanto que Valentín resulta tener un amorío con Juana María, la hija de Gudelio y nieta de Sofía, al tiempo que este se inicia en el negocio del narcotráfico. Dicho así, Narcedalia sería la tía abuela de Juana María y a la vez su hermana. En el transcurso de la trama, las actividades comerciales de Valentín se complican y llegan a poner en riesgo su integridad. A partir de esto, Narcedalia y su hijo planean una solución final que asegura a Valentín y compromete con dolo a Juana María con el mundo del narcotráfico.

La gravedad implícita de la resolución de la novela en la que se involucra directamente la integridad física y moral de Juana María exige revisar de cerca la conducta violenta de Narcedalia a la luz de los falsos positivos. Queremos dejar en claro que entendemos que ninguna situación violenta es comparable con otra y que el asesinato extrajudicial de civiles en Colombia nunca podrá ser equiparado con otros vejámenes, más aún cuando estos carezcan de una concatenación sociohistórica. Esta imposibilidad de generar analogías es incluso más difícil de sostener en casos como el que nos compete, en el cual son los acontecimientos de la llamada realidad aquello que ilumina la lectura de un texto de ficción. Sin embargo, aceptamos ir en contracorriente porque tenemos la convicción de que indagando al mismo tiempo, las vidas que leemos y las que vivimos, podremos encontrar un puente de conciencia individual entre lo real y lo ficticio que nos alerte del lado oscuro de la información mediática. Por eso, creemos necesario localizar herramientas teóricas que nos permitan la reflexión acerca de cada hecho violento, real o ficticio, más allá de su efímera y simulada espectacularidad, tanto en las pantallas televisivas como en las páginas literarias. En otras palabras, la falsedad de la conducta de Narcedalia, que resulta en la muerte de Juana María y su posterior socialización a través de la prensa escrita (en cuyos titulares Juana María aparece como una 
narcotraficante), podría habernos recordado lo que otros ya habían vivido, y habernos advertido lo que muchos otros estarían por vivir. Haber leído este tipo de textos con delicadeza nos hubiera hecho menos ingenuos acerca de la realidad proyectada en los medios porque gran parte de lo que vemos y oímos no es más que el frontispicio de quienes quieren multiplicar sus beneficios tal como lo hizo Narcedalia Vega. Haber leído a Narcedalia Piedrotas en su momento desde esta perspectiva nos hubiera recordado que en la vida todo se repite a menos que alguien recuerde lo que ya sucedió y actúe para evitar que suceda de nuevo. De ahí que volvamos a esta novela ya clásica con la premura de iluminar a Juana María y proponer un esquema de lectura que difiere de plano a estudios precedentes.

En uno de los estudios disponibles, Nora Guzmán asegura que el hacer de Narcedalia determina la entrada de Perdomo a una modernidad, lo cual permite localizar esta novela a principios del siglo XX. Período en el cual se da, por un lado, la modernización del norte de México y por otro, la apertura de Perdomo a un mercado internacional de mercancías. Según Guzmán, Narcedalia representa la dualidad (127) propia de las primeras décadas del siglo, que revela su empeño por las dinámicas comerciales sin haber puesto en cuestión su identidad conservadora y regionalista. Así mismo se señala el crecimiento de una clase media apolítica que encuentra en lo extranjero y en el lujo foráneo un propósito de vida, en cuyo seno el narcotráfico encuentra inmejorables aliados a ambos lados de la frontera. En otra investigación, Miguel Rodríguez Lozano sostiene que Elizondo Elizondo se vale de una escritura fragmentada para persuadir a su lector, de modo que este deba concatenar los personajes con los lugares para darle sentido a la obra y entender su irónico final (512). En particular, el autor señala que la inclusión del narcotráfico permea el relato con cierto carácter fugaz que es evidente en sus personajes. De acuerdo con esta lógica, la novela se ocupa de historias familiares y de personajes femeninos que transgreden las convenciones de dicha región desértica. Estas aproximaciones contraponen la necesidad de interactuar comercialmente con un afuera mientras que registran rápidas transformaciones sociales internas que redefinen el tejido cultural. Sin embargo, vemos aquí que estos 
enfoques se interesan en describir cómo el autor se apropia y documenta lo vivido, sin preguntarse acerca de las transformaciones sociales que trae consigo aceptar el capital como fin último.

Consecuentemente, aquí tomamos como partida de nuestro análisis el caso de Juana María para intentar abstraer otra aproximación a Narcedalia Piedrotas. Este desarrollo de ideas tiene en cuenta diferentes investigaciones en Colombia alrededor de los falsos positivos, entre las cuales queremos resaltar el trabajo realizado por la alcaldía de Bogotá, en cuyas páginas se define la aberrante ilegalidad de estos hechos:

El modus operandi utilizado en todos los casos supera la intención manifiesta de los implicados, en razón de que el reclutamiento en una zona alejada del teatro de operaciones de los acusados, la categoría social de las víctimas, los reportes generados para encubrir su asesinato, la escenificación de un combate en donde no se presentó, y el procedimiento engañoso que se utilizó para atraer a los muchachos hacia su propia muerte, son todos indicativos de que los militares no solamente conocían la ilegalidad de las muertes producidas, sino que también decidieron afectar los bienes jurídicos con el tipo de desaparición forzada de personas, en tanto que, con tal forma de actuar se garantizaba mantener el anonimato de las víctimas y privar a sus familiares de buscar la protección de la ley a favor de los jóvenes muertos (González Amado 203).

Es posible entrever en esta síntesis que el engaño es el mecanismo que permite la sucesión efectiva de hechos de acuerdo con un determinado esquema. Ya veremos adelante que al igual que en este caso el engaño invalida de plano la voluntad de las víctimas en cuanto nunca se dan por enteradas en que están siendo involucradas. De ahí que no exista resistencia alguna, al punto de que la muerte es lo que menos esperan las víctimas en medio de una seducción tejida mediante la siembra de ilusiones. Para poder entender esta misma dinámica en la novela y la importancia del engaño en la muerte de Juana María debemos considerar varias conductas que priman en 
lo descrito arriba, tales como la complicidad social; la seducción como instrumento del horror; el vaciamiento simbólico de la víctima; la judicialización y mediatización de los casos y, por último, las recompensas obtenidas por los victimarios. Vale advertir que más que hacer un tratado sobre cada una de estas nociones nos interesa ver las conexiones entre estas y su conjugación sistémica de modo que sirven a un fin único.

Al mismo tiempo hay que advertir que el engaño, y más precisamente "el engaño a los ojos", conduce dentro del dominio estricto de la literatura hasta la obra cervantina, donde colisionan frecuentemente la realidad y la interpretación -visual- de esta. De acuerdo con Américo Castro las constantes tensiones entre la realidad sensible a la que están expuestos los personajes y lo enunciado por estos conllevan una textura tan artística como ética (cit. por Wiger, 103-04). A partir de esto se ha sugerido que el "engaño a los ojos" que con frecuencia aparece en los diálogos cervantinos no obedece a un "problema epistemológico" como tal, en el que entra en juego el carácter ambivalente de una realidad, sino que implica diferentes perspectivas creadas por los personajes en las cuales la realidad aparece falseada (Martínez Mata 239-40). En consecuencia hay que considerar un estadio endógeno a la obra literaria en el que los personajes se cohesionan a menudo alrededor del engaño colectivo con el propósito de evitar el qué dirán, mientras que alguien permanece excluido de la verdad. Asimismo un estadio exógeno en el que participa un lector que siendo testigo de las tragedias que están ocurriendo padece el suspenso. En medio de esto se plantea entonces el suspenso emergente frente a la dicotomía de denunciar o no los hechos.

\section{El carácter de Perdomo: "Tú a lo tuyo"}

Para llevar a buen término un engaño es preciso consolidar una complicidad alrededor de un silencio que debe interrumpirse a medias. En la novela este silencio permanecería intacto a menos que ciertos agentes llamaran la atención acerca de lo que está ocurriendo. “Tú 
a lo tuyo" es la frase que utiliza Narcedalia para responderle desde el mostrador de su carnicería a una envejecida conciudadana que busca advertirle acerca de los rumores en Perdomo, que señalan a Valentín como un narcotraficante. "A palabras necias oídos sordos" parece ser el lema que justifica la confianza ciega que mantiene Narcedalia en su esposo, luego de que esta lo domara, proveyéndole una vida acomodada y vanidosa. Entre los beneficios se cuenta el uso de una lujosa camioneta que le obvia los esfuerzos que tenía que hacer siendo camarero antes de conocerla. En Perdomo todo se sabe de oídas pero nadie aparte de este personaje habla de lo que sucede sino al interior de sus viviendas. Allí existe un código social en el que todos se enteran de lo que está pasando pero nadie se atreve a decírselo ni a Narcedalia ni mucho menos a las autoridades. Enmudecen tal vez en una fútil espera de ver a Narcedalia desintegrarse ante la imposibilidad de controlarlo todo. Recordemos que Narcedalia domina Perdomo y por lo tanto no controlar a quien más cerca está de ella despierta el morbo. En un aparte el narrador nos explica esta situación: "Como caldo a punto de hervir . . con toda esa información pues sentían que algo estaba soberanamente gordo estaba por tronar. Ninguno quería perderse el tronido, así que espiaban, vigilaban, con los párpados caídos pero atentos. Bola de comadreros" (336).

Otra voz que sale a luz para denunciar lo que está ocurriendo es la del propio narrador. Se puede reconocer un narrador que toma partido y arremete sin vacilación en contra del comportamiento "comadrero" de los perdomenses que, cuestionando entre murmullos la historia de despojo que habita detrás de Narcedalia, siguen aceptando las oportunidades laborales que solo ella puede brindarles. La anterior crítica se hace más mordaz cuando el narrador animaliza la conducta de Perdomo. Para este no se trata únicamente de denunciar que los perdomenses sean chismosos, sino de revelar una arqueología de un conocimiento en la cual los sentidos configuran lo que allí se da por sentado. Para el narrador esto es muy grave, pues el conocimiento en Perdomo surge de darle libertad a un mundo gobernado por las apariencias, mientras que se va marginando el uso de la razón. Esta radical crítica se evidencia cuando el narrador 
dice que Perdomo "no es un perro, son mil perros oliscando por todos lados" (246). Aquí el narrador nos confirma lo dicho dejando en claro que Perdomo permanece en un estado de alerta vigilando y escudriñando la vida de los demás desde la distancia, sin contemplar un mínimo acercamiento con ese otro al que se olisquea o se mira. Bajo estas circunstancias es inviable una conversación de pares y por lo tanto la construcción del discurso depende de quién administre las miradas. En este punto entonces se reconoce un narrador que toma partido frente a esta actitud donde se esconde el meollo de muchas injusticias sociales, porque es a través de la percepción que unos imponen verdades sobre otros.

Finalmente, la falsa tranquilidad en Perdomo se interrumpe con la voz de Helvetia, quien es la enfermera y casi confidente de Juana María. Helvetia le advierte del peligro que corre al acercarse demasiado a Narcedalia, especialmente cuando lo hace a través de su relación con Valentín y más tarde con su hijo. En Perdomo, el chisme permite que la hipocresía fluya minando las posibilidades de Juana María ya que al ser la dueña de nada nadie le ofrece lealtad como a Narcedalia. Juana María entonces vive su vida sin darse cuenta de lo que está tejiendo a su alrededor y menos aún sin intuir la relevancia de esto para el desenlace de su propia historia. Se narran así miradas entrecruzadas, personajes que miran siempre a medias, personajes que miran con disimulo para nunca dar una versión certera de las cosas. En el relato son frecuentes las descripciones de quienes miran por encima de las bardas, por el rabillo del ojo o a través de ventanas (que se comparan con los ojos), dando lugar para que los perdomenses se apropien de la identidad de quienes son observados a través de la palabra. Dichas conversaciones que toman lugar de una calle a la otra aluden a un algo innombrable que solo se enuncia usando un código de indirectas que refiere a lo que todos creen saber pero pocos se atreven a traer a la luz. En este contexto las palabras de Helvetia son honestas pero no por esto dejan de hacerle eco a lo que el común de las personas en Perdomo tiene en mente. Helvetia le dice a Juana María: "tú sigues viviendo en el error, mejor búscate otro, manita, porque ése no cae, y si cae vas a estar bien embadurnada, cómo vas a creer 
que después de lo que haces con el padre su hijo te vaya a tomar en serio, no, olvídalo" (326).

Se infiere de lo anterior que Perdomo sabe que Juana María no posee nada en absoluto más que la trágica historia de su familia. Una historia de por sí, marcada por el qué dirán con respecto a su madre. Todos saben que Juana María es joven, humilde, soltera y habitante de Perdomo. Características que parecen enterrar a Juana en un determinismo decimonónico. Helvetia se lo recuerda aquí con disimulo al decirle que no espere ser tomada en serio por alguien que tenga poder y dinero o, mejor dicho, que no espere un futuro mejor del que vio al nacer. La condición marginal de Juana María le asegura de antemano el abuso según se lo dice Helvetia en la cita. Este orden de las cosas vuelve a indignar al narrador, quien se hace visible en el relato para criticar con insistencia la lectura determinista que Perdomo impone sobre Juana María. El narrador sintetiza esta actitud utilizando una analogía en la cual, si Juana María no tiene esperanzas de que la tomen en serio, tampoco Perdomo puede contemplar la ilusión de ser respetado en la capital mexicana. Al fin y al cabo, nos insinúa el narrador, ambos son una "arruga geográfica” (74), invisible para los centros de poder, un accidente.

Aquí vemos entonces un orden de las cosas asistido por una sociedad afincada en silencios a medias frente a Narcedalia y Juana María. Las razones para esta actitud devienen de posiciones diferentes, pues a pesar de que existe cierta admiración popular por ambos personajes en razón de su valentía para asumir lo cotidiano, el resentimiento y la moral, también prima el deseo de ver a Narcedalia y a Juana María desfallecer ante la fuerza de su sino. Al resolverse la trama, la conducta de Perdomo habrá de beneficiar a Narcedalia como empresaria, socavando a Juana María. Una triunfa como empresaria y la otra es asesinada. En esta última situación las habladurías, es decir lo simbólico, adquieren un poder tal que trastoca para siempre a esta humilde, soltera y habitante de Perdomo. El relato de Elizondo Elizondo nos empuja así a una geografía en la que se entrecruza el espacio y el poder para dibujar un lugar sin esperanza para sus habitantes. Un lugar que a pesar de los cambios económicos y su apertura transfronteriza no deja de ser visto desde 
la capital como una entidad difusa que se confunde con otros pueblos periféricos. Una región con un futuro borroso.

De la misma manera, la localidad de Soacha, anexa ahora a la capital colombiana, se ha visto como una manta progresiva de luces intermitentes en la que habitan ciudadanos como Juana María, sin futuro, como Helvetia describe a su amiga. Perdomo y Soacha comparten esa contradictoria invisibilidad visible, por cuanto ambos lugares existen de acuerdo a la gravedad de las cosas que allí ocurran y la connotación de esto para salvaguardar el orden y buen funcionamiento de la metrópoli. Por ejemplo en Perdomo se rompe esta invisibilidad a partir de la "espectacular" muerte de Juana María, apropiada por los medios de comunicación de la capital interesados en narrar ajustes de cuentas entre narcos. En Soacha fueron necesarias las muertes extrajudiciales de estos jóvenes para que los medios preguntaran por lo que allí ocurre con frecuencia. Solo así la atención pública se desvía por un momento para seguir con frivolidad estos acontecimientos, sabiendo que está muy lejos de conocer lo que "verdaderamente" está ocurriendo. A pesar de todo la experiencia mediática parece brindarnos un acceso cobarde a los horrores ajenos desde la condición de distante de lectores y televidentes, para los casos que trascienden la esfera de lo local. Resulta más atractivo y seguro ver todo esto con el rabillo del ojo, hablando a medias acerca de la realidad que otros nos informan, pero no por eso debemos dejar de preguntarnos: ¿qué sucede cuando optamos por dejar el mundo que vivimos en mano de terceros?

\section{La seducción: carne, corazón y titulares}

Uno de los aspectos más terribles que comparten los casos de Soacha y Perdomo es la forma en que se ejecutaron las acciones violentas sobre las víctimas. En ambos casos se siguió una metodología del horror que seleccionaba, identificaba y ejecutaba víctimas de acuerdo con un perfil específico. Para el óptimo funcionamiento de este mecanismo se creó al interior de las organizaciones criminales un organigrama en el que cada rol estaba suscrito a un fin 
común. Esta burocracia delictiva se describe cuidadosamente en los informes que han salido a la luz en Colombia y en cuyas confidenciales páginas se lee el objeto del operativo criminal. En la novela de Elizondo Elizondo esta metodología es diseñada por Narcedalia a puerta cerrada con su hijo. El lector es inhabilitado siéndole imposible tener una comprensión total de la maldad de Narcedalia, solo hasta que muere Juana María. El narrador nos advierte: "todos los demás serían títeres de su maquinación” (384-85) al punto que ni siquiera le preocupaba que "Vérulo espiaba. Las sirvientas espiaban. Perdomo espiaba. Ninguno de ellos podría atestiguar jamás que desde el primero hasta el último detalle fueron premeditados, y no podrían hacerlo porque les faltaban testimonios" (391). Pero si en ambos casos la información es administrada con sigilo hasta el final, una de las circunstancias más terribles de este actuar es que contempla la participación voluntaria de la víctima. Aquí los elementos antagónicos propios de un enfrentamiento civil o militar se desvanecen ante la inclusión de un sujeto que sin saberlo asegura que la operación marche de acuerdo con el plan maestro. Aquí la seducción de la víctima permite que esta se dirija "voluntariamente" hacia su propia muerte, presentándose a la mesa del victimario. Decimos voluntariamente en cuanto sus decisiones corresponden a las circunstancias que le proyectan los verdugos y que se refuerzan con la búsqueda que tiene la víctima de encontrar una oportunidad de vivir con dignidad.

Todo esto empieza a través de las promesas falsas que hace el victimario haciéndose pasar por quien no es. Su propósito es convertirse en el catalizador de los frustrados proyectos de vida de estos habitantes periféricos y ponerlos al servicio de los violentos sin que se haya necesitado un ápice de fuerza letal. El encantamiento de las palabras, la ilusión de un futuro, la construcción de una historia verosímil son las municiones que pausadamente se van administrando para evitarle a la víctima el dolor transitorio hacia su muerte. De un momento a otro la víctima pasa de estar buscando un mejor lugar en el mundo a ser asesinada. Las promesas aquí convocan a las futuras víctimas haciéndolas imaginar cómo el futuro puede ser menos peor. De este modo, las estrellas 
vuelven a brillar, los países con sus ciudades y sus periferias se ven menos injustos y más libres. Es solo a través de estas ilusiones perversas que la víctima y el victimario llegan a sentarse a la misma mesa como comensales sin que uno sospeche de las intenciones del otro. El lenguaje se convierte aquí en un artificio que excede los límites de la ficción comprobando su efectividad dentro y fuera de la literatura. Tanto en Soacha como en Perdomo se conduce una seducción forjada con palabras abriéndole paso a las balas.

En el caso particular de Soacha existen testimonios que dan cuenta del deseo que tenían las víctimas por "salir adelante", como suele decirse en Colombia. En el caso de Perdomo existe el relato que nos aproxima a los propósitos de Juana María para "progresar" como dicen en su pueblo. Por una parte, Linares Prieto, citando el estudio de Lemoine sobre la juventud marginada en Bogotá, nos advierte que los jóvenes en Soacha no piden de la vida ni más ni menos que otros jóvenes conciudadanos: tranquilidad sin corrupción, estudio y trabajo (22), refutando así la falsa idea de que los jóvenes marginados viven una desmedida ambición y que están dispuestos a cualquier cosa por alcanzar la gloria material. Por otra parte, el narrador de Narcedalia Piedrotas nos cuenta que Juana María también quería mejorar su vida a través del trabajo honrado, siguiendo el contrato social en Perdomo. A ratos se imaginaba a sí misma desempeñando trabajos que involucraran el talento matemático y administrativo que había heredado de la familia Vega en vez de simplemente cumplir con oficios que le garantizaran la mera subsistencia física. Leyendo Narcedalia podemos entender el código moral de Juana María, quien se engancha con Valentín por amor más no por su dinero. "Él [Valentín] le podría dar dinero, pero eso era volverse una zorra" (231-36), se nos aclara en el relato. Aquí se nos indica que Juana María, siendo una joven marginada, no estaba dispuesta a cualquier cosa para cambiar su situación social objetando la falsa idea de que las jóvenes marginadas están disponibles para ser seducidas con dinero.

Tanto en Soacha como en Perdomo, los prejuicios tienen un valor que sobrepasa lo simbólico y que en el caso de Juana María resulta letal. Su perfil la ha convertido en una potencial víctima ya 
que a la juventud marginada se concibe susceptible de actuar bajo el impulso exclusivo del lucro, incluso en contra de sus propios principios. En Soacha, los medios se apresuraron a mostrar una silueta que ratifica esta apreciación. A través de los primeros informes mediáticos la sociedad juzgó de inmediato culpables a quienes aún no se les había dado la oportunidad de defenderse frente a las cámaras ni en los estrados. Es horrible comprobar tras la difusión de investigaciones acuciosas que la mayoría de espectadores, incluyendo al presidente Álvaro Uribe Vélez, repitieron al unísono la versión castrense que daba a los jóvenes asesinados como criminales. Casi todos vimos el boletín de última hora sin cuestionarnos por la veracidad de los hechos. La verdad fue por un instante la amalgama auditiva del director del ejército, el presidente y la presentadora de noticias afirmando el resultado positivo del ejército tras sus operativos, mientras Soacha se convertía en un telón de fondo. Lo anterior se puede ratificar en artículos de circulación masiva como el periódico El tiempo o la revista Semana, pero prefiero citar el trabajo de Hollman Morris en su programa televisivo Contravía. ${ }^{7}$ Allí se escuchan los ecos que negaban la posibilidad de que los jóvenes dados como desaparecidos días antes de morir en "combate militar" hubieran salido de sus casas "con el propósito de trabajar o recoger café” (según Uribe Vélez). Lo anterior saca a la luz la inclinación social que criminaliza al joven habitante de la periferia, quien en su lucha diaria por mantenerse vivo y salir adelante se convierte en el mercado objetivo de la seducción criminal de quien en primera instancia debería protegerlo: el Estado.

La silueta que trazó Perdomo de Juana María se afinó voz a voz muy lentamente. Los medios de comunicación no tuvieron participación en este caso, o por lo menos nunca mientras ella estuvo viva. Juana María fue invisible hasta que la mataron y lo volvió a ser cuando la sepultaron, pero paradójicamente siempre estuvo en boca de todos los perdomenses. Ella fue la protagonista de una

\footnotetext{
tulos/.

${ }^{7}$ Los capítulos están disponibles en http://www.contravia.tv/espanol/capi-
} 
novela que otros imaginaron para ella. Al ser asesinada los titulares de prensa la acusaron sin demora de traicionar a Valentín, además de ser "dueña de una gran [indebida] fortuna" y de ser lista pero de haberse pasado de la raya (415-16). El día de su asesinato nadie tuvo tiempo suficiente para aclarar nada, ni siquiera para poner en duda lo que se decía de ella. Juana María murió en su ley, según se dijo en Perdomo, donde se masticaba otra vez el proverbio que reza: por algo sería que la mataron. El día de su muerte los perdomenses "de todos lados salieron, venían desbocanados" (413) al encuentro del cuerpo inerte de Juana María. La trama había concluido. Juana María estaba muerta para un Perdomo que desde ese momento decidió "no conocerla" (419). Este rechazo repentino nos enseña que las habladurías en Perdomo sumadas a la desinformación de la prensa metropolitana también negaron la posibilidad de que Juana María fuera una joven honesta que un día salió de casa a buscar el amor y se encontró con la muerte. Bajo estas condiciones de prejuicio social era impensable que Juana María no estuviera involucrada con el narcotráfico, pues la ambición que otros le imputaban la habría seguramente también puesto en contacto con los peores criminales transfronterizos. En Perdomo se sabe del peligro y lo tanto a partir de ese momento se calla y olvida.

El caso de Juana María está agravado por un hecho que estamos en obligación de aludir: su condición de mujer. El narrador de Narcedalia avanza denunciando la obsesión de Perdomo y revela un mundo lúdico sustentado en los sentidos. Perdomo se seduce con la vista y el olfato. Recordemos al parafrasear al narrador que Perdomo es un perro oliscando, muchos perros oliscando por todos lados. Mirando por encima de las bardas y olfateando a las vecinas, Perdomo descubre un placer idóneo en Juana María. Perdomo son todos hombres y mujeres sin excepción. Hablando, imaginando, disfrutando la carne ajena. También nos dice el narrador que incluso las mujeres recreaban a su modo lo que pensaban eran las costumbres carnales de la víctima (57). Los hombres sabían que "Juana tenía la piel de las piernas lustrosa, saludable, y su respiración levantaba sus pechos, bien, muy bien" (23). Ellas y ellos la habían visto y no podían negar que Juana María tuviera veinte años, "era bonita, 
más que bonita, apetitosa” (10) y que por lo tanto según su opinión se podía ajustar perfectamente al prejuicio de una ambiciosa zorra. Es decir, Perdomo pensaba todo lo contrario a lo que Juana María aspiraba a ser en su vida. Parecer apetitosa impedía que fuera una mujer de bien ante los ojos de Perdomo. Los hombres entendían por lo menos que Juana no aceptaba ningún tipo de insinuación sexual, pero a las mujeres esto no se les pasaba por la mente. Lo cierto es que tanto ellos como ellas sí conocían a ciencia cierta los antecedentes de la madre de Juana María. Dominado por un determinismo flagrante, Perdomo asumía que así como su madre, Juana María también tenía un "incendio entre las piernas" (119) y que por lo tanto era una entidad cóncava y viviente en espera de proveerle placer a quien se lo solicitara y más aún si el interesado era pudiente. Sin embargo, Perdomo seguía siendo un pobre perro y como tal, según sus cuentas, Juana María no le pertenecería jamás. Recordemos que Perdomo era un pueblo de subordinados a quienes les estaba vedado pensar en una relación con Juana María a excepción de Valentín y Víctor. A Perdomo le era imposible acceder a la carne de Juana María pero no su imagen a través de la cual terminaría al final por hacerse con ella.

Según hemos visto el engaño le debe mucho de su éxito a la condición de marginalidad de la víctima y a los prejuicios sociales. En ausencia de estos dos elementos sería imposible engañar a una víctima y salirse con la suya. Nadie de manera voluntaria caminaría junto a su victimario en busca de su propia muerte. El hambre de los jóvenes de Soacha y de Juana María, sus proyectos de vida insatisfechos y la apatía del resto de la sociedad los convirtió en una "presa" fácil. Los jóvenes están dispuestos a asumir iniciativas y riesgos que pueden ser utilizados de un modo perverso por quienes tienen el poder para disuadirlos. Esto no significa que estas víctimas estén siempre en disposición de traicionarse a sí mismos y sus valores por el afán de lucro. Lo peor de todo es que pase lo que pase en sus vidas a menudo se les imputará una culpabilidad por defecto, pues son la parte vulnerable de un convenio entre la sociedad y sus mentiras en cuyo epicentro habitan algunos medios de comunicación. A los jóvenes de Soacha, por ejemplo, les prometieron 
una oportunidad laboral que nunca se cumplió. Juana María salió a buscar el amor y no lo encontró. Al final vimos que la advertencia de Helvetia tenía una razón de ser y que puede aplicarse en otros muchos casos. Nadie la tomaría en serio. Juana María tenía veinte años, era apetitosa pero demasiado lista. Por eso la invisibilidad de estos sujetos se ha vuelto a instalar mientras que los titulares siguen alimentando las rotativas y haciendo eco de las versiones que le convienen al victimario.

\section{El método del horror privado}

En el análisis que nos ocupa se entrevé una metodología común para encubrir investigaciones judiciales que de manera sistemática alcanzan su máximo potencial cuando se implementa en otros contextos. Esta metodología aparece sustentada en la certeza de lo volátil que es el sentido de las pruebas materiales dentro de las investigaciones judiciales. De ahí que los victimarios planten a su favor evidencias para que luego durante las pesquisas solo emerja una conclusión que los beneficie y en cuyo seno las víctimas cargan con la culpa de los delitos. En el caso de Soacha, las evidencias materiales fueron la máxima para que tanto los agentes del Estado como los espectadores mediáticos criminalizaran a esos jóvenes asesinados en un remoto paraje de la geografía colombiana. Se les plantaron armas, uniformes y botas de caucho logrando que la escena del crimen resultara irrefutable: los jóvenes de Soacha no tenían "el propósito de trabajar o recoger café” y por ende su comportamiento estaba viciado, concluyó el presidente Uribe Vélez. Afortunadamente, la insistencia de la sociedad civil y de algunos organismos públicos como los centros de atención a los desaparecidos lograron que el ejército se retractara, poniendo en tela de juicio la importancia de las pruebas diseminadas. En dicho caso, la lógica de la cual se colige que el cadáver de un civil vestido con prendas de uso privativo del ejército es indiscutiblemente de un criminal resulta ser un fiasco. Un dolo que reveló el desgaste de una política de seguridad democrática sustentada en la repartición de recompensas en razón 
de operativos exitosos. Igualmente dañino resulta todo esto para el principio de legalidad en cuanto fractura la confianza en el proceder de sus instituciones. El Centro de Investigación y Educación Popular CINEP sintetiza esta situación así:

Se puede decir que la mentira se ha entronizado en el lenguaje corriente del Estado, falsificando circunstancias y contextos; fingiendo militancias y operativos; simulando falsos combates; estigmatizando comunidades y personas; imponiendo silencios bajo amenazas brutales que arrastran imágenes de cadáveres desfigurados generadores de terror; apelando a falsos testigos y a falsas informaciones ("Presentación" 8-9).

A partir de esto se justifica la apatía y el miedo social de pensar que el propio Estado criminaliza a ciertos ciudadanos, abriendo así una veta en la que prima el interés privado sobre el sistema probatorio.

En el caso de Perdomo, la erosión del principio de legalidad deviene de un interés netamente privado por demostrar el carácter intachable de Valentín. A través de este único objetivo se despliega toda la experiencia obtenida por Narcedalia en sus negocios, al tiempo que se revela una personalidad trazada por el desprecio a los seres humanos a excepción de su hijo y su marido. Utilizando este arsenal, Narcedalia manipula las instituciones del Estado y a los medios de comunicación, alineándolos a su servicio. El origen de lo anterior se desarrolla a partir de la conversación-confesión que mantuvo Valentín con Narcedalia, en la que este le revela cada detalle de su relación con Juana María y sus negocios de exportación de drogas hacia los Estados Unidos. Para ayudar a su esposo, Narcedalia propone un plan que de acuerdo con la novela se dará por terminado solo cuando los perdomenses y el gobierno no vuelvan a mencionar ni a Valentín ni a Juana María.

En este orden de ideas, la metodología de Narcedalia dicta que lo primero es engañar a Juana María a través de su hijo Víctor, quien deberá parecer interesado en una seria y honesta relación con ella. La parte final consistirá en hacer pasar a Juana María por una narcotraficante acusándola de los delitos imputados a Valentín. Víctor en 
calidad de primogénito disciplinado hace lo propio usando pocas palabras y esquivando las promesas. La estrategia contempla que Víctor maneje el auto de vidrios oscuros de su padre haciéndose pasar por él ante los ojos del pueblo, mientras exhibe a Juana María. Da vueltas por las calles de modo que Perdomo asume que Juana María sale con el padre y con el hijo. Al día siguiente, Juana María es tachada en Perdomo de cínica, indecente descarada y licenciosa $(399,396)$. De acuerdo con el plan, el engaño continúa después cuando Víctor la recoge ante los ojos de todos para pasar la noche en la frontera. Para ese entonces Víctor ya le ha dado a Juana María un paquete aludiendo que es un regalo para su madre. En ese instante además le entrega unos documentos argumentando otra excusa banal. La efectividad del engaño planeado por Narcedalia se verifica cuando Juana María por fin revela que se siente feliz. Allí deja entrever su esperanza en su búsqueda por un lugar en el mundo para ella que contradice lo dicho por Helvetia, quien predijo la imposibilidad de que alguien la tomara en serio. "Estoy enamorada . . cuánto quisiera ser su esposa" (400). En este punto ya vemos a Juana María cosificada y convertida en un cuerpo que debe ser dispuesto física y simbólicamente para persuadir al público acerca de algo premeditado.

Este engaño tampoco es gratuito. Víctor ha dosificado sus muestras de afecto cautelosamente, manteniendo silencios prolongados en los que sus primeros encuentros amorosos se desarrollan con una simpleza que roza el interés nato. Rápidamente la relación se intensifica al punto que Víctor alcanza a reflexionar acerca del riesgo que representa para el plan que perfeccionó su madre comprometerse de más con Juana María. Las dudas son pasajeras para Víctor, quien muy pronto reconoce sus lealtades. Así es que decide seguir adelante con el plan demostrándole un afecto viciado a Juana María, quien no hace otra cosa que sentirse reconocida cuando Víctor la va a buscar al trabajo enfrente de la expiatoria mirada de colegas y vecinos. Juana María asume el riesgo que esto representa sin imaginarse el alcance que en efecto tendrán los chismes en Perdomo. Al salir del trabajo, la confianza de Juana María se ve ratificada por el trato gentil de Víctor, quien no escatima detalles 
para mostrarle un mundo posible. La abundancia y lujo que la joven perdomense nunca había pensado vivir aparece con Víctor. Juana María es invitada a un hotel de lujo, en donde se sorprende al ver un refrigerador con comestibles y una cama con dimensiones extraordinarias. Luego, Juana María se maravilla en el restaurante con la diversidad del menú y de lo grato que resulta para ella no titubear por el precio al momento de ordenar un postre. A Juana María parece brillarle el mundo por primera vez pues está con un caballero, un hombre de su gusto, viviendo su momento olvidando quizá a propósito la advertencia de Helvetia y su cercanía con Narcedalia, quien muy pronto la convertirá en otro títere para salvaguardar a Valentín y su lucrativo negocio.

En este punto podemos inferir que Narcedalia supo aprovechar al máximo las condiciones sociales para ejecutar su plan. El engaño involucra en primera instancia la pasiva pero perversa participación de los perdomenses, quienes para este momento ya han instalado una falsa identidad sobre Juana María. Vimos en el párrafo anterior que Perdomo vuelve otra vez a enjuiciar a Juana María, ya no como habitante de un sector periférico sino sumándole una equivocada conducta moral sustentada en lo que está pasando frente a sus ojos. Es decir que no es aceptable que Juana María mantenga una relación con dos hombres y menos aún si estos tienen un vínculo familiar. La sospecha que pesaba contra Juana María, la joven apetitosa, se vuelve irrefutable, de manera que al final, cuando aparecen los titulares de prensa haciéndola pasar por quien no es, nadie se sorprende de su supuesto comportamiento criminal. De lo anterior se deriva entonces la pregunta: ¿por qué razón no podría ser también una narcotraficante? Lo cierto es que como estratega Narcedalia entiende y habita esa lógica que gobierna en Perdomo en estos asuntos. Según nos informa el narrador, Narcedalia es un ejemplo de la persistente moral ranchera de corte machista y homofóbica (242). Ella, al igual que el narrador, sabe que Perdomo saca sus conclusiones de la mera observación de sus habitantes. Narcedalia sabe también que Perdomo usa ese mismo blasón para definirla a ella misma, empero, intuye que en Perdomo el hecho de tener un cálculo escalofriante, de usar pantalones o de portarse como macho no 
son razones suficientes para acusarla de inmoral. En otras palabras, Perdomo no le permite a Juana María creer que pueda tener una mejor vida, acusándola por partida doble dada su juventud. Por esta razón, Perdomo se convierte en virtud de su reiterado voyerismo en otro títere del esquema ideado por Narcedalia.

De la misma manera, Narcedalia se conoce bien a sí misma, logrando equilibrar sus fortalezas y debilidades, de forma que sus planes estén siempre asegurados. En lo profesional, Narcedalia se reconoce como una emprendedora independiente pero además se ve como poseedora de una capacidad logística que le permite actuar en perfecta comunión con los narcos, las instituciones oficiales y los medios. En lo personal, su fealdad e inapetencia sexual completan un perfil que siempre aterroriza a su contraparte e incluso al mismo Valentín, quien al "saber de lo que ella era capaz" (384) por su familia y sobre todo por multiplicar sus negocios siempre queda sorprendido. La palabra de Narcedalia es ley. Dicho así Narcedalia en ningún momento teme involucrarse en negocios con quienes hasta solo unas semanas antes habían amenazado a Valentín mostrándole fotografías amarillistas de sujetos torturados. En esas fotografías aparecían hombres a quienes les arrancaban las uñas, las orejas o a quienes les rociaban ácido en la piel. Pero para Narcedalia esto carece de suficiente peso para deponer sus proyectos. Narcedalia sabe tomar decisiones estratégicas. Ella tantea aquel riesgo pero acepta que las ganancias potenciales pueden justificar cualquier lucha. Para ese entonces en Perdomo ya se ha iniciado una guerra entre los narcos y los organismos del Estado cuyo resultado se evidencia en la muerte del mensajero de Valentín. Este hombre apareció "medio muerto por los golpes, con las vísceras estalladas y los oídos reventados, con los dedos de los pies desechos por los pisotones -venía sin zapatos y sostenido por sus compañeros- y visibles peladas de cráneo por los increíbles estirones que había recibido" (370). Vemos que las reglas de este enfrentamiento obedecen al capital más no al principio de legalidad, pues al desatarse la violencia cada grupo hace lo suyo para defender sus intereses. La ley del talión vuelve a imponerse. Mientras tanto Narcedalia y su familia saben guardar la compostura en medio de esta batalla. 
Esto facilita que mucho después de alcanzar su objetivo, Perdomo le confiera títulos honoríficos por sus contribuciones al pueblo y su quehacer político. Poco importó en Perdomo que Narcedalia viera la vida como una carrera por vengar la muerte de sus hermanos y que su odio contra el mundo se hubiera enconado casi que por casualidad en Juana María. Su pelea contra el mundo (50) escudada en una moral ranchera la garantiza que siga siendo una ciudadana de bien.

Desde la perspectiva de Narcedalia querer a los humanos carece de sentido en especial si estos la han traicionado, como nunca lo haría una mascota. De ahí que Juana María sea una pieza más para su estrategia familiar y empresarial que no despierta ninguna compasión. El engaño finalmente se materializa cuando Juana María sale de su casa pensando que va a verse con Víctor sin imaginarse que va al encuentro de su asesino. El narrador nos relata cómo en un instante Juana se convierte sin resistencia en un mero cadáver, en un "costal de huesos y carne": "Con silenciador la mataron. Cada matón disparó dos veces. Ni ellos mismos supieron quién le dio el tiro de gracia. Juana no entendió, murió sin entender. Sus ojos se quedaron abiertos, ingenuamente abiertos bajo el cráter negro, escupitajo sangriento, que un disparo le abrió en la frente. Juana murió sin darse cuenta" (412).

A partir de este momento todo avanza rápido y la trama empieza a resolverse. En Perdomo todos salen apresurados de sus casas a comprobar lo que sabían que iba a ocurrir. Las personas presentes hablan solo de las evidencias de la escena mientras los investigadores catean la casa de Juana María, recuperando las cosas que Víctor le había dado a guardar para incriminarla en el negocio de la droga. Lo que ocurre aquí tiene una gravedad altísima que el narrador sabe focalizar. En palabras del narrador, Juana María al ser asesinada es convertida, por gracia de su asesino, en un costal. Escoger este sustantivo para definir la situación de Juana María no es un hecho arbitrario pues lo que se quiere denotar es el vacío que se posesiona de Juana María, quien a partir de ese entonces será juzgada por su silueta y por la situación que la rodea. Las pruebas que la incriminan serán pues el sustento para desarrollar teorías acerca de quién era Juana María "realmente". Su cuerpo sin vida ilustra la instantánea 
transición hacia un costal que vaciado de sentido ni siquiera merece el señalamiento de un asesino en particular. Es absolutamente perverso entonces que ni siquiera su sicario sepa si fue él quien la mató o no y por lo tanto la distribución de la responsabilidad civil y moral de su muerte esquiva un asidero definitivo. En breve, la falta de comprensión de lo que estaba ocurriendo, sumada a la negación de señalar un victimario, nos hace pensar en la deshumanización de Juana María.

Esta situación de agravio a la dignidad humana empeora con la criminalización de Juana María. Al momento de ser asesinada todos los prejuicios que pesaban sobre ella son utilizados por quienes conducen la investigación. En la distancia, Valentín, Víctor y Narcedalia están satisfechos porque el plan está funcionando a la medida. Pero no pasa lo mismo con el padre de la víctima. Para este el horror está por empezar y por eso no tarda en gritar frente a su hija "nada hemos hecho, señor, somos gente buena, mi hija no era una delincuente" (415). Sus palabras además de estremecernos nos revelan la desconfianza que se tiene en el sistema judicial y por eso se apresura a defender a su hija de las imputaciones que hasta ese momento nadie había enunciado con palabras. Es decir, el padre está refutando una acusación que no se había formalizado en un documento oficial pero que él anticipaba, considerando el comportamiento de los perdomenses y su subordinación a las ordenanzas de la metrópoli. Tampoco nadie le había dicho que Valentín era un narco pero, desde que intuyó que su hija salía con quien no debía, el también temió lo peor para ella, como si se hubiera puesto de acuerdo con Helvetia. El padre de Juana María compartía la certeza de que nadie tomaría en serio a su hija, ni siquiera el sistema judicial. Ahí mismo, la voz de Gudelio recoge toda la tensión alrededor del cuerpo inerte de Juana María, que yace ahora como culpable sin haber tenido la oportunidad de una legítima defensa.

En Perdomo, que Juana María hubiera pasado de ser un sujeto con un bajo perfil que vivía al filo de la invisibilidad a estar en las primeras páginas de los diarios nacionales no era suficiente. Ahora, Juana María debía morir como una narcotraficante. Según se narra en esta escena, fotógrafos desconocidos aparecen en Perdomo para 
tomar instantáneas del cadáver y de su casa facilitando que los espectadores conozcan las evidencias del sumario. Las fotos publicadas al mediar entre los investigadores y las evidencias se convierten ellas mismas en la prueba que compromete a la víctima. Aparecen allí ilustrados los paquetes que Víctor le había dado a la víctima, haciendo irrefutable todo lo ilustrado en las fotos. Al poco tiempo, las fotografías junto a los artículos que las acompañan reciben premios por su calidad periodística, mientras que al otro lado de la frontera los narcos advierten que han empezado los mejores días para su negocio. Como suele decirse, Narcedalia había matado a dos pájaros de un solo tiro. Por una parte, su Valentín estaba a salvo y su negocio habría de expandirse, al punto que tendría muy pronto un aeropuerto privado. Por otro lado, ella misma habría corregido su buen nombre familiar, el cual, de acuerdo a las circunstancias de Perdomo es fundamental para el efectivo ejercicio de los negocios y la multiplicación del capital.

\section{Guerras ganadas, vidas perdidas: una narca menos}

En última instancia podemos concluir que el caso de Juana María está vinculado a una política en la cual cada narcotraficante abatido que aparece en los titulares de los diarios representa un avance positivo en la guerra antidroga. Juana María es una representación muy bien lograda de aquella estadística vacía que se consume a través de los medios de comunicación, impulsando la ingenua creencia de que al eliminar a ciertos actores sociales junto con su mal se van a resolver las profundas problemáticas sociales. Al ser asesinada Juana María, Perdomo se funde en un silencio incómodo, es decir, en un lugar común en el cual todo muerto en combate es culpable de algo. El contexto viciado en el que vive Juana María manipula su comportamiento, abriendo un espacio para ser juzgada y luego abusada por su condición humilde, soltera y apetitosa. Es así como Juana María se convierte en una "arruga geográfica", invisibilizada por un sistema que toma como punto de partida una serie de prejuicios que nadie acepta y que muy pocos refutan en un 
momento de crisis estructural, tras haber perdido la esperanza de tener una vida mejor.

Estos antecedentes nos permiten volver al ejemplo de Soacha en el que pudimos ver un patrón de comportamiento similar. Allí, las muertes de los jóvenes fueron rápidamente apropiadas por los medios de comunicación, que en su prisa por transmitir estadísticas que respalden la labor del gobierno en curso pasaron por alto preguntarse si aquellas fotografías e informes proveídos por el ejército nacional podrían estar viciados. Podríamos decir que no es oficio de los medios descreer de las instituciones del Estado, pero podríamos también afirmar que tampoco lo es asumir como irrefutables los informes del gobierno y sus anuncios públicos. Por eso resulta de interés que en este caso también los jóvenes asesinados hayan sido víctimas de un sistema en el que los prejuicios sociales y la manipulación judicial se acoplan para dar por culpable a quien todavía no ha tenido la legítima oportunidad de defenderse. En este caso vemos que el mismo Estado motiva los intereses privados y no al contrario, como ocurre en el otro caso discutido. Aquí las recompensas económicas mantienen a flote un enfrentamiento por sacarle provecho al conflicto en Colombia. No cabe duda que este caso es solo un ejemplo más de la industria de la guerra. Afortunadamente, la denuncia de los llamados falsos positivos ha servido para poner en tela de juicio el valor del acervo probatorio fotográfico con el que se acusó a los implicados y así revelar una metodología del horror en la que participaron agentes del Estado, abriendo una veta para que no se disponga tanta confianza en las imágenes.

Por lo tanto la lectura asincrónica de estos acontecimientos en Perdomo, México y Soacha, Colombia, nos ha permitido entender que tanto en la ficción como en la realidad se utilizan mecanismos propios del engaño para construir visiones de mundo sustentadas en las apariencias. Allí los prejuicios se imponen sobre ciertos ciudadanos, quienes viviendo al margen de los privilegios llegan a ser criminalizados por verse de cierta manera o por el hecho mismo de habitar una geografía no metropolitana. Esto pone en evidencia una manera de conocer el mundo que se reproduce, fijando sobre los sujetos juicios de valor que emergen de discursos orquestados 
por unos cuantos en busca de beneficios particulares. En Perdomo esto se articula a través del chisme y los prejuicios de un pueblo que conoce a través de los ojos limitando las escasas oportunidades que surgen cerca de la frontera de los Estados Unidos. Allí es constante un estado de vigilancia cobarde que se ensaña en particular sobre aquellas jóvenes a quienes encima de todo Perdomo utiliza para lubricar abusivamente su imaginación sexual. Narcedalia dispone con habilidad de su profundo entendimiento de los habitantes de Perdomo y del sistema judicial para tomar ventaja y luego postularse sin ninguna vergüenza como ciudadana ejemplar. Su moral ranchera se convierte en la herramienta que le permite prolongar su control sobre los sujetos y sus negocios sin ningún inconveniente, desplegando el negocio e incluso inaugurar un aeropuerto privado. La lectura de la novela Narcedalia Piedrotas contrapuesta a la realidad histórica colombiana y sus políticas de seguridad democrática permite reconocer entonces las aplicaciones del engaño dentro y fuera de la ficción, de manera que se sugieren pautas para cuestionar las verdades alrededor de la violencia.

\section{Obras citadas}

“Carta del Presidente de la República, Álvaro Uribe Vélez”. Política de Defensa y Seguridad Democrática. Presidencia de la República / Ministerio de Defensa, 2003, pp. 5-7. Organización de los Estados Americanos, hwww.oas.org/csh/spanish/documentos/ Colombia.pdf.

Construcción de memoria, Estado y medios, tomo 4, Alcaldía Mayor de Bogotá, 2011.

Elizondo Elizondo, Ricardo. Narcedalia Piedrotas. México: Fondo de cultura económica, 2002. Impreso.

"False positives are systemic: UN Rapporteur". Semana, 19 junio 2009, www.semana.com/international/articulo/false-positives -are-systemic-un-rapporteur/104271-3.

Flores Nava, Juan José. "Lo que no puede ser pronunciado en palabras difícilmente existe". El Financiero, 22 marzo 2007, pp. 38-39. 
González Amado, Iván. "Informe sobre ejecuciones extrajudiciales en el caso Soacha". Construcción, pp. 99-123.

Gúzman, Nora. Todos los caminos conducen al norte: la narrativa de Ricardo Elizondo Elizondo y Eduardo Antonio Parra. Fondo editorial de Nuevo León, 2009.

"La historia desconocida de los falsos positivos". Semana, 11 junio 2011, http://www.semana.com/nacion/articulo/la-historia-desconocida-falsos-positivos/241215-3

Linares Prieto, Patricia. "Desaparición y asesinato de jóvenes de Soacha por parte de miembros de la fuerza pública: dimensión de una tragedia incomprendida". Construcción, pp. 11-98.

Martínez Mata, Emilio. "No hay historia humana que no tenga sus altibajos. Haz y envés en el Quijote”. El ingenioso hidalgo (Estudios en homenaje a Anthony (lose). Editado por Rodrigo Cacho Casal, Centro de estudios cervantinos, 2009, pp. 233-46.

"Presentación". Colombia, deuda con la humanidad 2: 23 años de falsos positivos. CINEP, 2007, pp. 8-9.

"Report of the Special Rapporteur on Extrajudicial, Summary or Arbitrary Executions, Philip Alston". 28 mayo 2010, pp. 1-36, Office of the High Commissioner UN Human Rights, www.ohchr.org.

Rodríguez Lozano, Miguel G. "Notas en torno al mundo narrativo de Ricardo Elizondo Elizondo". Literatura mexicana, vol. 9, no. 2, 1998, pp. 495-519.

Weiger, John G. The Substance of Cervantes. Cambridge UP, 1985, pp. 103-04. 